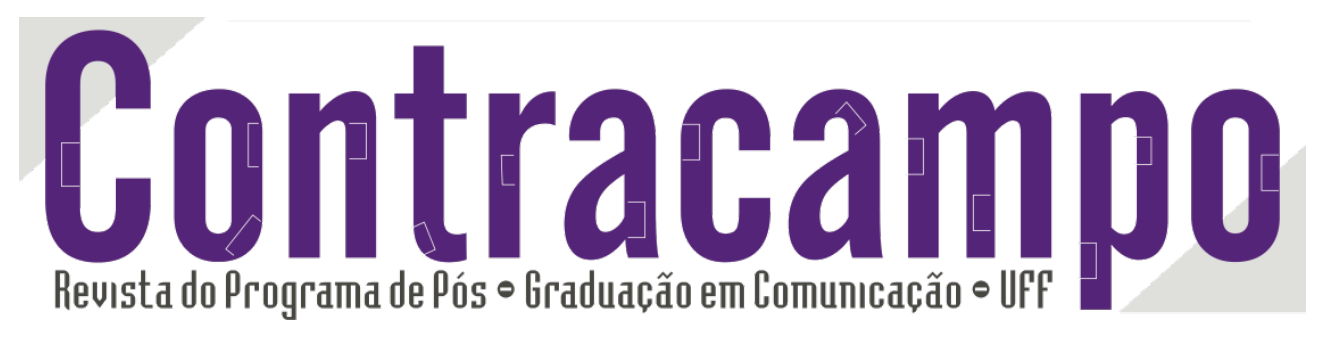

\title{
Comunicação e automação no metrô de Paris: primeiras interfaces $^{1}$
}

Communication and automation in the Paris subway: first interfaces

${ }^{1}$ Uma versão inicial deste artigo foi apresentada no II Congresso Mundial de Comunicação Ibero-Americana (CONFIBERCOM 2014), 13 16 abril 2014, Universidade do Minho, Braga, Portugal.

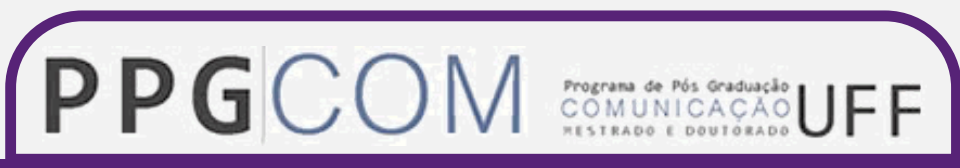

Ao citar este artigo, utilize a seguinte referência bibliográfica

CAIAFA, Janice. Comunicação e automação no metrô de Paris: primeiras interfaces. In: Revista Contracampo, v. 30, n.1 , ed. agosto/novembro, ano 2014. Niterói: Contracampo, 2014. Págs: 60-82.

\section{Edição $30_{12014}$}

Ensaio temático "Tabloidização da mídia"

Contracampo

e-ISSN 2238-2577

Niterói (RJ), v. 30, n. 1, ago.-nov./2014

www. uff.br/contracampo

Enviado em: 30 de jun. de 2014

Aceito em: 30 de jul. de 2014

A Revista Contracampo é uma revista eletrônica do Programa de PósGraduação em Comunicação da Universidade Federal Fluminense e tem como objetivo contribuir para a reflexão crítica em torno do campo midiático, atuando como espaço de circulação da pesquisa e do pensamento acadêmico. 


\section{Resumo}

Este texto apresenta alguns resultados da pesquisa que realizo sobre a reconfiguração dos circuitos comunicacionais na Linha 14 e na Linha 1 do metrô de Paris, as duas linhas da rede em que a condução dos trens é totalmente automatizada. A automação integral da condução trouxe consigo a introdução de um novo modelo organizacional que tende a se generalizar para todo o sistema e que implica uma redistribuição da presença humana, junto com a maquínica. Aqui examinamos as ressonâncias dessas mudanças nas primeiras interfaces que 0 usuário precisa construir, à entrada do metrô, para poder viajar. Tentamos elucidar as modalidades comunicativas que acompanham a divisão de trabalho particular entre humanos e máquinas que parece ter se estabelecido ali, em parte como resultado dessas interferências no meio sociotécnico do metrô.

Palavras-chave: Processos Comunicativos; Inovação Tecnológica; Metrô.

\section{Abstract}

In this article we present some results of the research on the reconfiguration of communicative circuits on Lines 1 and 14 of Paris subway, both totally automated. Full automation of conduction brought a new organization model that tends to generalize to the whole system and which involves a redistribution of both human and machinic presences. Here we examine the resonances of these changes in the level of the first interfaces in which the subway riders have to engage, at the subway entrance, in order to travel. We try to elucidate the modalities of communication that accompany the division of labor between humans and machines which prevails in this context, due partly to these interferences in the sociotechnical milieu of Paris subway.

Keywords: Communicative processes; Technological Innovation; Subway. 


\section{O metrô, um medium}

onsidero o metrô como um grande sistema de comunicação — onde os dispositivos tecnológicos deflagram mensagens sonoras e visuais e os viajantes que ali circulam produzem interfaces entre si e com a máquina.

Num metrô, muitas operações são automatizadas e realizadas a distância a partir de um posto central de controle. No PCC os operadores humanos trabalham com um conjunto de computadores que supervisionam e controlam todo o processo de movimentação dos trens e $\mathrm{o}$ funcionamento dos equipamentos elétricos $\mathrm{e}$ eletromecânicos nas instalações do metrô. Os outros computadores do sistema — por exemplo, os equipamentos embarcados que podem ser responsáveis totalmente ou em grande parte pela condução dos trens - enviam informação para o PCC, que emite relatórios, fazendo circular os dados necessários para a operação do metrô.

Mensagens são dirigidas aos usuários a partir de suportes técnicos — avisos sonoros durante as viagens, painéis visuais para orientação e controle do movimento dos fluxos humanos. Os usuários abordam constantemente as máquinas para poder viajar (as máquinas de bilhetes, os torniquetes para poder entrar, ou as portas das composições, e ainda os dispositivos de comunicação remota com os agentes). Agentes e usuários circulam nos espaços das estações — onde a comunicação face a face entre eles pode se estabelecer - e dos trens, que se movimentam em constantes idas e voltas, como um carrossel. Os circuitos comunicacionais no metrô formam uma superficie de interfaces em que se articulam incessantemente o trabalho das máquinas e a agência humana.

Podemos ver o metrô como um conjunto de circuitos comunicacionais ainda com mais proveito se trabalhamos com uma acepção menos restrita de comunicação. David Morley (2011, p. 2) propõe uma expansão do conceito de comunicação de forma que fosse possível explorar as "mobilidades diferenciais" no mundo contemporâneo, estipuladas "pela regulação de mensagens e de pessoas".

André Lemos tem desenvolvido trabalhos em que explora a relação entre comunicação, espaço e mobilidade. $\mathrm{O}$ autor define o movimento de pessoas, 
commodities e objetos como uma dimensão da mobilidade junto à dimensão informacional: "comunicar é deslocar" (LEMOS, 2009, p. 28). A sociabilidade, a política, a cultura e a subjetividade se produzem, afirma, na "dinâmica tensa" que se compõe com esses fluxos heterogêneos. Os dois aspectos da mobilidade são indissociáveis e em alguma medida se implicam mutuamente, já que causam impacto um sobre o outro.

A perspectiva que desenvolvemos aqui - ao considerar os fluxos materiais e os semióticos no quadro dos fenômenos comunicacionais - evoca igualmente os argumentos de Felinto (2001) por uma abordagem material da comunicação inspirada na teoria das materialidades, que se desenvolveu no Departamento de Literatura Comparada da Stanford University. Uma abordagem material da comunicação não envolve somente afirmar que o ato comunicativo se apoia num suporte técnico e que retira daí algumas propriedades, mas que ocorre sempre incorporado numa materialidade abrangendo os suportes assim como todo o conjunto de interações entre heterogêneos que o ato envolve e os processos socioculturais e políticos que em parte o condicionam. Ou, então, na linguagem de Deleuze e Guattari (1980), diríamos que os atos comunicativos existem agenciados, como componentes de um agenciamento concreto.

Bakhtin (2002) mostra como a enunciação se recorta de uma "corrente de comunicação ininterrupta", que envolve a palavra do outro e que se inscreve numa "situação extralinguística". A enunciação aparentemente individual é socialmente orientada, composta ela própria dessa materialidade feita de determinantes discursivas e não discursivas, fatores de uma "expressão externa". Sá (2004) retoma as afirmações de Felinto para mostrar como o campo da comunicação já seria fértil dessa insistência na materialidade, explorando contribuições de autores de referência da perspectiva da teoria das materialidades, McLuhan e Benjamin, e outras que o campo da comunicação abrigou, como o trabalho de Espen Aarseth.

Ao longo destas afirmações que, embora com inserções diversas, em vários pontos se aliam, nossa perspectiva permitiria não apenas incluir os estudo dos transportes - a mobilidade de pessoas e objetos - no campo da comunicação, mas também evidenciar essa inscrição material dos fluxos semióticos. 
Este texto apresenta alguns resultados da pesquisa que realizo sobre a experiência de automação integral da condução no metrô de Paris, que hoje tem duas linhas totalmente automatizadas, a Linha 14 e a Linha 1. Evoca também, pontualmente, minha pesquisa sobre a Linha 4-Amarela do metrô de São Paulo, totalmente automatizada e inspirada no modelo francês. ${ }^{1}$ Nesses dois trabalhos, assim como naquele que realizei sobre o metrô do Rio de Janeiro (CAIAFA, 2013), exploro através de pesquisa etnográfica e com preocupações particulares em cada caso - a construção da mobilidade num sistema de transporte tomado ele próprio como um medium.

O diálogo com um conjunto de interlocutores - entre engenheiros, agentes e usuários do metrô de Paris -, que venho cultivando, e minha própria experiência como usuária no contexto da observação participante me permitiram estas primeiras indicações. ${ }^{2}$ Apresento em seguida algumas dessas vozes, ao lado da minha, e fragmentos de relatos de campo, além de uma tentativa de análise.

\section{A automação e os metrôs}

O espaço do metrô é povoado de dispositivos técnicos. Cunhei a expressão ambiente maquínico (CAIAFA, 2013) para nomear esse espaço físico e social em que o componente tecnológico tem grande centralidade. "Maquínico", no texto de Deleuze e Guattari (1980), refere-se à máquina técnica mas também ao caráter de engrenagem dos arranjos sociais, o que permite forçar uma diferença em relação a "mecânico" e recolocar o técnico e o humano como processualidades num contexto complexo de relações.

\footnotetext{
${ }^{1}$ Realizo o trabalho sobre o metrô de Paris como pesquisadora convidada no CSI (Centre de Sociologie de l'Innovation) da École Nationale Supérieure des Mines de Paris, com bolsa Estágio Sênior da CAPES. Agradeço à CAPES e à equipe do CSI, sobretudo a Madeleine Akrich, Alexandre Mallard, Fabien Muniesa, Sayonara Leal, Marcelo Formazin e Catherine Lucas. Sou grata também a René Schérer, Eduardo Viveiros de Castro e Bruno Latour. Agradeço ao CNPq pelo apoio à pesquisa sobre o metrô de São Paulo.

${ }^{2}$ Agradeço, entre os profissionais do metrô de Paris, sobretudo a Edgar Sée, Corinne Schwebbel, Daniel Audoux, Louis Villier, Jean-Christophe Delprat e Michel Fayolle, e ainda a Georgia Louge, Philippe Desseroir e Serge Soler. Sou grata a Caetano Jannini, do Metrô de São Paulo, a Mauricio Dimitrov, da ViaQuatro e a Anne Timbert e Adeline Mayeur.
} 
Observamos que cada vez mais, ao longo da evolução da tecnologia e do pensamento metroviários, os dispositivos técnicos assumem um papel central na operação do sistema e como mediadores das relações no ambiente do metrô.

Trata-se, em parte, do fenômeno mais geral das transformações da produção econômica e subjetiva nas sociedades capitalistas. Ao mesmo tempo, é interessante observar como o movimento para a automatização, que ocorre evidentemente em vários outro setores, apresenta-se no transporte metroviário, quando a questão é conduzir pessoas a partir de um aparato sociotécnico que imbrica constantemente os fluxos maquínicos com a ação humana. Explorar como se apresenta, em suma, num contexto de imprevisíveis e de aventura - aspectos que, afinal, acompanham os deslocamentos humanos e costumam estar associados à viagem.

É importante igualmente observar as vicissitudes da automatização em cada contexto específico de um sistema numa cidade, com os aspectos socioculturais que acompanham e mesmo reinventam todo o processo localmente. Assim, os debates que marcam a recepção e a adoção de uma tecnologia, as tensões que se geram e como se resolvem ou persistem, não são circunstâncias incidentais, mas a matéria mesma de que se fabrica a vizinhança entre as pessoas e os objetos técnicos em relações multifacetadas e em parte imprevisíveis. Michel Callon (2006), ao escrever sobre as controvérsias técnicas, afirma que se tem, nesse caso, "un monde en train de se faire" (um mundo a se fazer).

Num metrô, são muitas as operações que vão sendo automatizadas. A venda de bilhetes, por exemplo, já o é, em grande parte, no metrô de Paris. Outro exemplo são os dispositivos de leitura automática dos títulos de transporte nas linhas de bloqueio (torniquetes), muitas vezes equipados com portas que, no caso de um título não válido, vedam a entrada de seu portador. São substitutos do fiscal humano - no caso de Paris, do remoto "poinçonneur", evocado por alguns usuários com quem tenho conversado, que se encarregava de conferir e perfurar o bilhete, controlando assim a entrada dos passageiros.

A condução dos trens é o caso mais fascinante e arriscado da automação nos metrôs. Os sistemas de ajuda à condução num metrô a automatizam em algum grau e são os antecedentes mais ou menos imediatos dos sistemas de automatização integral. Num primeiro nível de automação, denominada Condução Manual 
Controlada, o piloto humano conduz o trem com auxílio de um sistema de proteção que não permite que se ultrapasse o limite de velocidade estabelecido em certo trecho da via e freia numa emergência. Na modalidade Piloto Automático, o sistema conduz o trem e o piloto humano se encarrega de abrir e fechar as portas, além de assumir o controle no caso de falha. Nos terceiro e quarto níveis, a condução é totalmente automatizada. Na modalidade denominada DTO (Driverless Train Operation) mantém-se um agente a bordo para intervir em situações emergenciais. Na modalidade UTO (Unattended Train Operation), também chamada "unmanned", implementada tanto no metrô de São Paulo quanto no de Paris, não há nenhuma presença humana a bordo e todo o controle é feito à distância no PCC. ${ }^{3}$

Mundialmente, a automação integral da condução foi de início implementada em veículos simples e em sistemas de pouca demanda. São os pequenos veículos que conduzem os passageiros num aeroporto, por exemplo. A automação integral da condução é um empreendimento muito mais complexo quando se trata de sistemas de metrô pesado, ou seja, com veículos de maior gabarito e alta demanda. É o caso dos metrôs de São Paulo e de Paris. Em São Paulo, a Linha 4-Amarela, ainda com apenas algumas estações inauguradas, transporta uma média de 650 mil passageiros num dia útil. A Linha 14 parisiense transporta em torno de 500.000 passageiros por dia. A Linha 1 parisiense tem demanda próxima à da Linha 4 do mesmo sistema, a próxima a ser automatizada, ou seja, em torno de 740 mil passageiros por dia. ${ }^{4}$

A presença dos passageiros, curiosamente, é o fator de maior risco para automatização integral. Há uma brincadeira entre os profissionais da Linha 14 que consiste em reconhecer, com humor, que sem os passageiros daria tudo certo. Isso não quer dizer que essas linhas não funcionem bem, ao contrário, mas é interessante reter este ponto para tentar compreender as relações complexas entre humanos e máquinas no contexto das viagens de metrô.

\section{O metrô de Paris}

\footnotetext{
${ }^{3}$ Para uma análise das vicissitudes da modalidade unmanned no Metrô de São Paulo, cf. CAIAFA, "Automação e presença humana na Linha 4-Amarela do metrô de São Paulo". Para mais detalhes sobre os diferentes níveis de automação, cf. Metro Automation Facts, Figures and Trends.

${ }^{4}$ Veja, respectivamente: http://www.viaquatro.com.br, La ligne 14 fête ses 14 ans e Communiqué de Presse, STIF.
} 
O metrô de Paris inaugurou sua primeira linha, a Linha 1 - Porte Maillot-Porte de Vincennes, hoje estendida até La Défense e Château de Vincennes - em 19 de julho de 1900. A cidade de Paris se encarregava da infraestrutura e a companhia privada CMP (Compagnie du Chemin de Fer du Métropolitain de Paris), do material rodante e da operação. Em 1949, uma nova organização foi criada para gerir os transportes da região, a RATP (Régie Autonome des Transports Parisiens), um estabelecimento público de caráter industrial e comercial dotado de autonomia financeira (GUERRAND, 1999; PINÇON e PINÇON-CHARLOT, 2001). Hoje a RATP opera os transportes públicos na região de Ile-de-France ${ }^{5}$ através de quatro redes: ônibus, metrô, RER $^{6}$ e tramway.

Durante as primeiras décadas que se seguiram à inauguração da linha pioneira, em 1900, o metrô parisiense se expandiu rapidamente, constituindo um conjunto de 13 linhas. Ao mesmo tempo, e por muitos anos em seguida, foram sendo construídas extensões do traçado dessas linhas, e hoje as estações terminais muitas vezes chegam às zonas periféricas, os "banlieues". Somente em 1998 foi inaugurada uma nova linha, a 14, resultado de projeto pioneiro e ousado de metrô automático, o projeto Météor (Métro Est Ouest Rapide).

Anos depois, em 2010, a RATP realizou pela primeira vez a automatização integral da condução de uma linha existente — justamente a Linha 1, a primeira do sistema. Todos os profissionais da RATP com quem conversei até agora enfatizaram a particular complexidade de se automatizar uma linha construída e em funcionamento.

Desde o final dos anos 1980 a RATP ingressou num processo de "modernização", denominação utilizada por meus interlocutores. A implementação de uma linha automatizada e a conversão de outras existentes para essa modalidade de condução dos trens se inserem nesse processo. Meus interlocutores enfatizaram este ponto e também é dessa forma que vários autores que escrevem sobre a RATP se referem a esses acontecimentos (DAVID, 1995; LÉFEBVRE, 1993; VILLOUTREIX, 1990).

\footnotetext{
${ }^{5}$ A lei de descentralização de 2 de março de 1982 criou a "região", uma "coletividade territorial" que reúne um conjunto de "departamentos". Ile-de-France é uma região constituída de 8 departamentos: Paris, Val-de-Marne, Seine-Saint-Denis, Hauts-de-Seine, Yvelines, Val-d'Oise, Seine-et-Marne e Essonne. No momento há um projeto de reorganização das regiões francesas envolvendo algumas fusões e em que a região de Île-de-France permanece inalterada.

${ }^{6}$ O RER (Réseau Express Régional) é um metrô expresso regional que liga Paris aos subúrbios em torno. Caracteristicamente, o metrô expresso regional atende zonas mais afastadas do centro urbano, é de grande gabarito, com demanda expressiva, e suas estações são mais afastadas entre si do que no metrô urbano. (ALOUCHE, 1990).
} 
A modernização do setor de receita, iniciada nos primeiros anos da década de 1990, com a automatização da venda dos títulos e do seu controle, também fez parte desse movimento que envolveu uma grande reforma gestionária e a introdução de novas tecnologias (LE NENAON e PERREAU, 1992).

Nesse contexto, as transformações não são apenas tecnológicas, embora estas tenham sem dúvida um papel impulsionador, mas também organizacionais. Um novo regime de gestão humana foi implementado, implicando uma reorganização do trabalho do metroviário e, o que nos interessa particularmente, uma reconfiguração dos circuitos comunicacionais de grande monta.

Em graus diferentes e de diversas maneiras, os executores desses grandes projetos tendem a vê-los como inelutáveis - o que a princípio não é tão surpreendente, já que, afinal, agimos em nosso trabalho e em nossas vidas porque apostamos em uma certa necessidade. Em se tratando de uma inovação tecnológica, a percepção dessa necessidade pode se impor com força particular. Ora, Michel Callon (2006, p. 137) assinala que, se queremos compreender os mecanismos presentes nos processos de adoção de uma tecnologia, deveríamos abandonar a ideia de uma "pura necessidade técnica", e considerar um campo em movimento de numerosos e variados atores, debates e negociações. É justamente o ângulo de análise de uma "controvérsia" que permite explodir essa "ilusão".

$\mathrm{Na}$ mesma linha de pensamento, Bijker e Law afirmam que as tecnologias surgem de conflitos e resistências e que "os protagonistas buscam estabelecer ou manter um arranjo tecnológico particular" (1996, p. 9).

De fato, se admitimos que não há uma necessidade na base de um arranjo tecnológico estabelecido - rompendo igualmente, nesse contexto, com o modelo da eficiência para explicar as escolhas técnicas (HESS, 2007) — resta-nos buscar a variedade das vozes e posições. E, ainda — o que é particularmente importante numa pesquisa etnográfica - , procurar conhecer as facetas do corpo a corpo na vivência concreta de todas estas transformações.

Nova configuração comunicacional 
Além da supressão do posto do condutor, a automatização integral da condução trouxe toda uma reorganização do trabalho dos agentes na RATP. Houve uma aproximação entre funções de operação e manutenção, mais enfatizada na Linha 14, mas também presente na Linha 1 e em algum grau nas linhas clássicas ou não automatizadas. A tendência, mais ou menos pronunciada ao longo do sistema, é de uma polivalência das funções do agente, que pode, por exemplo, fazer trabalho de atendimento e de manutenção de primeiro nível (primeiros socorros dos equipamentos). Como me descreveu um agente, há aqueles que "fazem um pouco de tudo". A manutenção de maior envergadura, contudo, se conserva como especialização.

Nesse novo modelo de organização e gestão do trabalho humano as tarefas desempenhadas in loco são minimizadas e o trabalho se realiza em grande parte e tanto quanto possível a distância, a partir do PCC. As intervenções tendem a não se dar antes de tudo diretamente sobre os objetos, mas através de transmissões a partir de uma comunicação entre máquinas. Os agentes interagem, em geral, pontualmente entre si, acompanhando e supervisionando o trabalho da máquinas. Na Linha 14, há, no início e no final da jornada de trabalho, um "briefing", como me explicou Corinne Schwebel, Responsable Transport (responsável pela movimentação dos trens em todos os seus aspectos) da linha. Os agentes incumbidos das diversas tarefas se reúnem e tomam conhecimento, juntos, do que há a fazer. É um momento de comunicação humana face a face que acompanha, nesse caso, o tipo de cooperação que o trabalho numa linha automatizada requer. Joseph (2004) menciona e descreve a prática do briefing na operação da Linha 14.

Ocorreu, ao mesmo tempo, uma redução de pessoal, embora sem demissões este detalhe sendo responsável, segundo me relatou um interlocutor, pela relativa aceitação dessas transformações por parte dos empregados da empresa. Le Nenaon e Perreau (1992) explicam também dessa forma a "calma relativa" que reinava na época dos inícios da automatização da venda de bilhetes. A rede se expande e os agentes são remanejados, sem necessidade de novos custos de pessoal, já que a máquina assumiu várias funções. Como me disseram membros do quadro diretor da empresa, esta se encontra num movimento de produtividade.

Assim, há hoje em cada estação do sistema um único agente em posto fixo. Equipes itinerantes percorrem o espaço das estações, executando tarefas como o 
controle de bilhetes, com o objetivo de detectar e punir os calotes (aliás frequentes), e outras que dizem respeito à repressão a delitos e à supervisão dos espaços em geral. Há também agentes chefes ("agents de maîtrise") em algumas estações. No caso específico das linhas automáticas, estes trabalham em alguns períodos do mês no PCC e, em outros, na linha, supervisionando o trabalho dos agentes de estação. Como me explicou um engenheiro da empresa, essa dupla inserção do agent de maîtrise é um dos aspectos da polivalência de funções. A automatização, ao mesmo tempo que substitui em alguma medida o humano pelo automatismo, reconfigura a sua distribuição nas tarefas e nos lugares.

A polivalência do trabalho do agente se realiza em vários níveis ou intensidades, dependendo da linha. Plenamente realizada (ao menos no projeto, pois por vezes o quotidiano transforma os planos) nas automáticas, é menos presente nas linhas "clássicas" e um pouco mais nas "intermediárias", ou seja, as que foram modernizadas mas não automatizadas. Essa classificação das linhas, que me foi explicada por um condutor com quem conversei, mostra bem o movimento progressivo do processo de modernização na empresa.

A polivalência tampouco diz respeito apenas às funções ligadas à movimentação dos trens, caracterizando também o trabalho de estação. Além de poder intervir sobre os equipamentos nas linhas automáticas, em todo o sistema os agentes de estação podem exercer sucessivamente as funções de agente de controle (segurança), agente comercial e assistente de operação (que, segundo me explicou um agente de estação, realiza uma supervisão local numa linha, trabalhando, por exemplo, com avisos sonoros aos usuários). Essas mudanças foram introduzidas no quadro do chamando Nouveau Service Station (NSS, Novo Serviço Estação), que data dos primeiros momentos da modernização (LE NEANON e PERREAU, 1992; THIÉRY, 2002) e que vigora até hoje. Os agentes de estação numa linha clássica também podem fazer pequenos serviços de manutenção, como trocar uma fechadura, como me relatou o interlocutor citado acima.

O projeto de implementação de uma linha com condução integralmente automatizada (o projeto Météor, que criou a Linha 14) já existia nos inícios de 1990, quando a nova presidência da empresa deflagrou o processo de reformas no quadro da modernização. Encontrava-se, contudo, esquecido, e recebeu grande impulso nesse 
contexto, tendo figurado com destaque nas declarações de intenção da nova equipe como o arauto do futuro do sistema (DAVID, 1995). Em seguida, a inauguração da 14 — envolvendo a introdução de uma inovação tecnológica de grande porte e ao mesmo tempo uma nova maneira de conceber o trabalho de operação do metrô - funcionou, segundo tem sido possível constatar nesta pesquisa, como uma ratificação das mudanças que já vinham sendo praticadas. A implementação de um sistema integrado de automatismos é uma mutação de monta num metrô e interfere diretamente na organização da presença humana.

De fato, parece que a inovação tecnológica, de certa forma, surge para efetuar essa ratificação das mudanças organizacionais em curso e para garantir algumas outras. É o que tem se passado no metrô de Paris, segundo pude constatar. Villoutreix (1992) escreve que a introdução de uma nova tecnologia torna-se quase um pretexto para que as reformas organizacionais se realizem. Trata-se de um processo complexo de implicação mútua em que a tecnologia parece em alguns momentos estar a serviço de algumas apostas — por exemplo, a da redução de pessoal a favor de uma presença maior da máquina e a da polivalência no trabalho humano. Ambas estão ligadas ao controle de custos. A polivalência se justifica também, em parte - como me explicaram alguns interlocutores membros dos quadros diretores da empresa - pela necessidade de vigiar e controlar o trabalho maquínico, mais complexo agora, mais sutil e mais exigente.

É um novo regime de interfaces que emerge dessas reconfigurações maquínica e humana. O predomínio das relações a distância e a reorganização das funções dos agentes, a presença mais expressiva da máquina - tudo isto afeta as superfícies de contato ao longo dos circuitos híbridos humano/máquina do metrô que é preciso abordar para fazê-lo funcionar e também para poder viajar.

Trataremos em seguida das primeiras interfaces que o usuário enfrenta no metrô de Paris ao tentar adquirir seu título de transporte, transpor as linhas de bloqueio (os torniquetes) e entrar no sistema. São os contatos que o usuário estabelece diante de barreiras potenciais à sua entrada nos acessos e mezaninos do metrô (patamares intermediários entre os acessos e as plataformas) com os agentes e as máquinas ali presentes. No metrô de Paris essas interfaces se inscrevem hoje no novo regime que as mudanças técnicas e sociais trouxeram ao sistema. Fatores de ordem sociocultural 
contribuem ao mesmo tempo para a construção dessas experiências no contexto específico do metrô de Paris.

Diante de máquinas e guichês: primeiras interfaces

À entrada das estações de metrô os usuários encontram hoje sobretudo máquinas onde podem comprar bilhetes unitários ou recarregar passes temporais. Há lugares que têm máquinas e um guichê de informação apenas, e não de venda de bilhetes. Mais raramente, encontramos um guichê de venda ao lado das máquinas. Há outros, com menos espaço, em que não há nem máquina nem agente — mas certamente mais adiante haverá outro acesso que conduzirá a algum dos dois. Naquele espaço as barreiras vão se interpor em algum grau à sua entrada, ou seja, agentes e máquinas podem se apresentar mais ou menos disponíveis para franquear ou impedir a sua passagem.

A automatização da venda dos bilhetes não acompanha necessariamente a automatização da condução dos trens, ao mesmo tempo em que numa linha clássica a distribuição de bilhetes já pode ter dispensado o vendedor humano. A condução totalmente automatizada, contudo, costuma dar lugar a outros automatismos no edifício do metrô. A introdução de todos esses automatismos ocorre, em geral, no contexto de transformações organizacionais, como temos visto, sob a rubrica de uma "otimização" ou "modernização" do sistema. É o caso de São Paulo e o de Paris. No metrô de Paris a venda automatizada de bilhetes predomina em toda a rede.

Todos os usuários com quem falei até agora indicam como evidente a redução de pessoal nas estações e a maioria não aprecia este aspecto, embora haja os que são indiferentes. De fato as experiências nesses ambientes mais povoados de máquinas variam, sendo que estas são em geral consideradas de fácil utilização.

Comenta Rémy:

Para as pessoas que estão habituadas, particularmente as novas gerações, fazem com facilidade, eles se habituaram. Para os que não se habituaram é extremamente desagradável.

Armelle recarrega seu passe temporal (válido por um mês) nas máquinas:

É fácil, mas é verdade que às vezes elas não funcionam. 
Para Katherine, é fácil recarregar o passe temporal na máquina. As máquinas funcionam bem, salvo o rolinho que é preciso operar para escolher o que se quer comprar (um bilhete, um carnê de bilhetes etc.):

É irritante porque é difícil acertar, ele rola e você ultrapassa. Isso é chato, né?

É interessante a presença desse rolo nas máquinas de bilhetes. Trata-se de um dispositivo mecânico, de movimentação um tanto aleatória frente às teclas, que só requerem um toque. Precisa da destreza humana para funcionar a contento.

Sophie utiliza sem problemas as máquinas, mas tem preferência pela presença humana nos acessos e em geral no metrô:

Agora, eu prefiro que haja um condutor, prefiro que haja alguém na bilheteria, sempre. A automatização, confesso, tenho problema com isso de maneira geral.

Minhas tentativas para comprar, pela primeira vez, um passe temporal (chamado "carte navigo"), válido por um mês, geraram um bom trecho em meu caderno de campo.

Tudo começou num acesso da Estação Denfert-Rochereau na Avenida Général Leclerc. Ali há um guichê de informação e quatro máquinas de bilhetes. Na semana anterior eu já havia esperado muito na fila desse guichê, vazio, e finalmente desistido. $\mathrm{O}$ aviso no monitor sobre a mesa dizia: "Je reviens en quelques minutes" (volto em alguns minutos). Em seguida a frase aparecia traduzida em inglês, alemão e italiano. Diante da ausência do agente e da espera longa e inútil na fila, dirigi-me então à máquina, aprendi como operá-la e comprei bilhetes unitários. Na segunda ocasião eu retornava ao mesmo acesso para me informar sobre a compra mais complexa de um passe temporal, esperando encontrar alguém nessa segunda vez. De fato, havia um agente no guichê de informação. Ele afirmou, na ocasião, que essa compra poderia se feita na máquina. Não valia a pena comprar naquele momento porque estávamos no meio do mês e eu perderia vários dias.

Chegada a hora de comprar o passe, voltei ao mesmo lugar, mas constatei que a máquina só me permitia recarregar um passe já adquirido. Concluí que não havia entendido bem nem o que a máquina fazia e nem o que o agente poderia fazer por mim, 
e entrei na fila para falar com a agente que se encontrava no guichê. Ela me informou (contrariando o que eu acabara de constatar) que seria possível, sim, comprar na máquina, mas, como eu era residente, poderia obter "gratuitamente" o passe num guichê - o que queria dizer que eu não pagaria 5 euros pelo plástico, exigidos pela máquina. Mas era preciso levar identidade e atestado de residência. Poderia fazer essa compra com ela? Sim. Alertou, por outro lado, que eu poderia chegar ao guichê e não encontrar alguém que pudesse fazer essa venda mais complexa (que envolve tirar uma foto e outros procedimentos para produzir o passe). Nem todos os agentes estavam preparados para isso. E ela, ao que afirmou, estava. E até quando ficaria ali? Até 7 horas da noite. Ainda era o meio da tarde.

O que me atraiu foi poder resolver logo o assunto e, como morava ao lado, saí correndo para pegar os documentos. Retornei uns dez minutos depois para constatar que a senhora já não estava no guichê e uma fila se formara.

Resolvi dirigir-me a um outro acesso próximo onde havia guichês de venda. Ali a agente me disse que eu poderia, sim, comprar o navigo naquela estação gratuitamente, e me deu um bilhete especial para entrar e ter acesso ao local de venda, chamado "agência comercial". Quando me aproximei do lugar vi que havia uma multidão esperando, muito mais gente do que na fila do outro acesso. Saí então e dirigi-me, novamente, a este. Mas já ao descer as escadas vi que a fila estava bem maior. Apesar da frase em tantas línguas, "dans quelques minutes", a agente não havia voltado. Entrei na fila, esperei, me cansei finalmente e fui ter às máquinas. Tocando aqui e ali os lugares da tela descobri um caminho até o passe - afinal, o primeiro agente com quem falei havia me dito, com segurança, que eu poderia fazer a compra na máquina, e a agente ausente agora também, assinalando que eu teria de pagar pelo plástico. Ora, naquela altura, aceitei pagar e, na ausência do humano e depois de tantas entradas e saídas, acolhi de bom grado a interface mais garantida que a máquina me oferecia.

Introduzi 5 euros. A máquina engoliu e expeliu um pequeno cartão, do tipo bilhete de papel. Era uma espécie de vale-passe-navigo: "1 Bon pour Navigo Découverte". Descobri, então, que era apenas isto que a máquina estava autorizada a fazer, produzir um vale, porque em seguida mandou que me dirigisse a um guichê de venda. Mas não era possível comprar na máquina? Dois agentes haviam informado que sim. Certamente consideravam "comprar" pagar 5 euros por um vale de um passe 
futuro. Mas isso não resolve o problema de quem quer viajar. Para mim aquilo não era comprar um passe navigo. A máquina, por sua vez, mandou procurar um guichê.

A máquina delegou para o humano e o humano não estava mais.

As máquinas se mostravam impotentes e os humanos ou eram pouco loquazes na explicação, ou poderiam não saber fazer o trabalho a eles delegado, ou simplesmente não estavam em seu posto.

Não foi ainda naquela ocasião, portanto, que comprei o passe. Desisti e comprei bilhetes unitários, possibilidade que a máquina oferecia. No dia seguinte encontrei naquele acesso de novo uma fila e nenhum agente. Fui, ainda mais uma vez então, ao outro acesso — onde, como já relatei, há guichês de venda e uma agência para confecção do passe. A agência, aquela que tinha uma multidão no dia anterior, estava fechada. Fui até o guichê de venda, ainda sem saber ao certo o que iria acontecer - o que era ou o que não era possível fazer num guichê, numa máquina. Finalmente, quando apresentei aquele cartão "descoberta" que havia custado 5 euros na máquina, a agente me vendeu um passe de 65 euros e 10 centavos válido por um mês. Eu mesma deveria colocar a foto, já que eu não estava comprando como residente. Complicado? Foi assim que me pareceu também.

Madeleine Akrich (1992), ao descrever os objetos técnicos, escreve que eles contêm uma "geografia de responsabilidades", em que se determina quais tarefas se deve delegar a quem ou a quê. Na mesma linha, Bruno Latour (1992) também prefere expressar essa situação em que parte do trabalho cabe a artefatos técnicos em termos de uma "delegação" de tarefas a "não-humanos". Assim, haveria que considerar, antes de tudo, uma "distribuição de competências" entre humanos e não-humanos. Para o autor, as distinções entre esses dois personagens têm menos importância do que a "cadeia completa" em que se distribuem as competências e as ações. Não são as extremidades que importaria considerar (de um lado o humano e de outro o técnico), mas as "gradações" ao longo da cadeia. O engenheiro justamente trabalha sobre a gradação, ele "viaja" ao longo dela, nisso consiste a sua habilidade. Trata-se de uma "trajetória" em que humanos e máquinas podem ser designados para tarefas na medida, segundo se determine e creia, da sua confiabilidade para executá-las.

Justine, que viaja diariamente de metrô, utilizando inclusive as linhas automatizadas, observa, referindo-se às aventuras nos acessos: 
Para mim o agente deveria estar lá para vender bilhetes e para dar informação. Mas para mim o seu principal trabalho é vender os bilhetes e não vejo bem o que ele faz. Está lá meio assim... Às vezes não há ninguém. Às vezes se precisa de fato de uma informação e não há ninguém.

Há um embaralhamento na distribuição das tarefas entre máquina e agente, na "geografia" de delegação que envolve o humano e o não-humano. Nenhum dos dois parece preparado e o primeiro, ao receber a maior carga, pode não estar presente. Além disso, o humano (o único a quem é possível dirigir um pergunta fora da programação) pode não deixar claro ao usuário a divisão de trabalho entre ele e a máquina. Talvez, na pior das hipóteses, para se eximir de tarefas que sabe que tem pouca condição de cumprir (nem todos estão aptos a realizar os procedimentos para a venda de passe navigo a residentes), talvez porque desconheça de fato como se faz exatamente (devido, novamente, ao fato de que nem todos têm a mesma preparação), ou talvez simplesmente por um estilo lacônico, que aliás a máquina - programada, como se sabe, por humanos — também tem.

Trata-se aqui sobretudo das necessidades de visitantes, turistas, de novos moradores ou de qualquer outro que precise iniciar um processo. Para os moradores de longa data - como a maioria de meus interlocutores - esses processos se automatizaram e o começo já recuou no tempo.

Em conexão com este ponto, são interessantes as aventuras de Justine em duas ocasiões: quando perdeu seu passe navigo anual e quando suspendeu sua assinatura e depois precisou retomá-la. Em ambas ela enfrentou, subitamente, um começo e seu relato é também de dificuldades. Houve, de início, um processo de busca de informação. Ela supunha que poderia solucionar o problema ali no guichê ou pelo site da empresa e não esperava ter que trilhar todos os passos de confecção de um passe numa agência (aquele lugar que, quando por minha vez eu tentava comprar o passe mensal, estava tão cheio que finalmente desisti). Reconquistar um título de transporte foi, segundo me contou, um processo burocrático e custoso. Observou:

As agências não se encontram em toda parte e, quando se tem que ir lá, é preciso ter tempo porque demora muito. 
Em trabalho anterior (CAIAFA, 2013), estudei a implantação de um novo sistema de bilhetagem eletrônica no metrô do Rio de Janeiro. Mostrei como as opções técnicas - o que era possível inscrever nos novos cartões, onde a leitura desses títulos poderia ser feita, o tempo de utilização dos títulos e dos valores registrados - eram indissociáveis de uma política tarifária, evidentemente de autoria humana, e que, naquele caso, muito subtraía ao usuário.

No caso do sistema de bilhetagem do metrô de Paris - com o seu regime particular de delegação a agentes e a máquinas, e os acidentes dos encontros nos acessos - o laconismo dos humanos e das máquinas, além da possível indisponibilidade dos primeiros, dificulta um primeiro contato com o metrô e mesmo uma necessidade súbita de recomeço que requeira, para o usuário, aprender e realizar novos gestos.

É possível que a política de redução e redistribuição de pessoal, no contexto, como já vimos, do processo de modernização e de automatização do sistema (não só da condução, mas também das tarefas ligadas à receita), tenha um papel nessa situação. Por exemplo, em toda a rede o agente não trabalha mais numa única estação, em que antes ele permanecia e que aprendia a conhecer. Prevalece o "attachement unique" (vínculo único), à linha e não à estação, como me explicou Daniel Audoux, agente líder ("agent de maîtrise") da Linha 1. O enfraquecimento do vínculo com o local poderia ter um papel, por exemplo, no problema da ausência do agente (que eu constataria muitas outras vezes) ou na pouca disposição para informar com detalhe. E, ainda, a polivalência no trabalho do agente, mesmo bem organizada e limitada, poderia estar contribuindo tanto para a irregularidade na aptidão dos agentes de atendimento (nem todos são preparados para preparar um passe temporal) quanto para essa dificuldade que têm em passar uma informação detalhada. Ao ocupar-se de várias coisas, é inevitável, ao menos para os humanos, que não se dedique tanto empenho a cada uma delas.

No contexto do Nouveau Service Station, em vigor desde os primeiros tempos de reforma no início dos anos 1990, como vimos, o agente se torna polivalente, exercendo as várias funções pertinentes ao trabalho de estação. Daniel, que mencionei acima, observou, contudo, que um agente de estação não muda de tarefa numa mesma jornada de trabalho. Por outro lado, nas linhas automáticas se espera dele que realize ainda outra tarefa, desta vez não relacionada com o trabalho de estação, o serviço de manutenção 
emergencial das portas de plataforma, se estas apresentarem algum defeito. Trata-se das portas instaladas ao longo da plataforma e que se abrem e fecham sincronizadas com as portas do trem. São dispositivos de segurança fundamentais nas linhas automáticas, em que não há condutor para gerir as interfaces complexas entre trem e plataforma, e requerem constante cuidado. Compreende-se como o envolvimento dos agentes de estação nessa tarefa decorre, como me explicou Louis Villier, engenheiro que trabalhou nas duas linhas automáticas, da grande reatividade que é preciso produzir frente a avarias e imprevistos no contexto dos complexos automatismos. Decorre também, em alguma medida, da redução de pessoal em campo que a automatização e o movimento de produtividade, conjuntamente, determinam.

Finalmente, o problema da informação incompleta ou sucinta poderia ser uma realização de uma situação mais geral na cidade ou na sociedade mais ampla, questão de difícil abordagem e de que não trataremos aqui, mas que de toda forma é curioso observar na própria máquina. Mensageira, em última instância, dos humanos, ela pouco diz, apesar de fazer a sua parte com alguns poucos toques do usuários, e enfim mandar procurar um agente.

Ao longo da trajetória que se percorre como um continuum (de um a outro e de volta), as competências específicas de agentes e máquinas acabam por não ter muita chance de se afirmar. A divisão de trabalho ou delegação de tarefas entre humanos e máquinas pode produzir, para o usuário (ou cliente, na terminologia que a RATP estipulou também como uma ferramenta de modernização), no caso de alguns tipos de bilhete e em certos momentos, uma situação insolúvel de dependência dos dois.

Entre agentes e máquinas, no que tange a situação de uma primeira compra de um passe temporal, o percurso é acidentado e os dois não se entendem muito bem. A interface, portanto, não se oferece facilmente ao usuário ou cliente. É ele que vai ter que realizar o encaixe, como uma espécie de operador de ligação e de interface - colhido nesse entremeio onde um e outro, a máquina e o humano, podem se omitir mais ou menos, por diversas razões.

Um usuário estrangeiro, que havia experimentado dificuldades para se tornar um usuário frequente, comentou que, uma vez que conseguimos entender como fazer e nos 
inserimos no sistema, tudo se torna fácil. De fato, a certa altura, entrar, embarcar e, quando necessário, renovar o título de transporte (os passes temporais), torna-se um percurso sem entraves num metrô eficiente como o de Paris. Em seguida, a viagem, em geral, também vai fluir. O intervalo breve e o serviço contínuo são evocados pelos usuários com quem até agora pude conversar e eu mesma, como usuária, não cesso de constatar estes aspectos.

Os clientes de longa data, como vimos, prescindem, inclusive, da presença humana nos acessos - e, como constatei, não parecem sentir falta do condutor durante as viagens, embora alguns não simpatizem com a automação como princípio - , já que automatizaram, por sua vez, todos os percursos no sistema. Como escreve Joseph (2002), o direito à cidade também é o direito à distração. Em contraste com o que se passa na pequena aldeia, nas grandes cidades somos menos identificáveis e mais ao abrigo de solicitações (CAIAFA, 2002). Prosseguimos distraídos e a natureza de nossos contatos se diversifica: temos que inventar novas formas de diálogo quando estamos entre desconhecidos e tanto o silêncio quanto a palavra podem ser mais criativos (TARDE, 1992; CAIAFA, 2002, 2007, 2013). Nesse contexto, a máquina pode nem ser menos calorosa que os humanos.

De toda forma, há ocasiões - como por vezes nos primeiros momentos para ingresso no metrô ou no caso de imprevistos durante as viagens - em que o repertório humano é mais adequado para efetuar as tarefas, e pode se fazer indispensável. Sobretudo se o "script" da máquina (AKRICH, 1992), programada pelos humanos e refletindo suas escolhas e desejos, se furtar a seguir o cliente até o fim.

É certo, igualmente, que a automação e o que as empresas denominam otimização (palavra que ouvi de um interlocutor em São Paulo) ou modernização colocam problemas de vulto para o trabalhador do metrô. Meus interlocutores membros dos quadros superiores da RATP argumentam que haveria uma valorização do trabalho do agente e um novo tipo de cooperação no contexto dessa organização do trabalho. Alguns agentes com quem conversei falam, ao contrário, em perda nas relações sociais e na construção do saber ferroviário. Um deles vê todas estas medidas como derivando, apesar de todo o discurso que tenta justificá-las, do imperativo de redução de pessoal. ${ }^{7}$

\footnotetext{
${ }^{7} \mathrm{Em}$ "'C' comme 'conducteur': l'automatisation intégrale de la conduite et la reconfiguration des circuits communicationnels dans le métro de Paris" discuto estas posições dos interlocutores.
} 
Em qualquer caso, nas plataformas e nos trens, tanto quanto nos lugares de acesso às estações do metrô de Paris, vigora esse regime especial de interfaces de humanos e máquinas que a automação e os novos imperativos organizacionais em parte determinam e que se investe de características específicas neste contexto sociocultural. As ressonâncias dessas transformações são diversas e é importante continuar observando. Os espaços para o acesso ao sistema são lugares particularmente sensíveis na medida em que ali se constroem os primeiros gestos da hospitalidade que se prepara para nós no metrô.

\section{Referências bibliográficas}

AKRICH, Madeleine. The De-Scription of Technical Objects. In: BJKER, Wiebe E.; LAW, John (Orgs.), Shaping technology/building society: studies in sociotechnical change. Cambridge: The MIT Press, 1992.

ALOUCHE, Peter. A Tecnologia dos Metrôs do Mundo. Revista dos Transportes Públicos, ANTP, São Paulo, Ano 12, No 49, 1990.

BAKHTIN, Mikhail. Marxismo e Filosofia da Linguagem. São Paulo: Hucitec, 2002.

BIJKER, Wiebe E.; LAW, John. General introduction. In: BIJKER, W. E.; LAW (Orgs.). Shaping Technology/building society: studies in sociotechnical change. Massachusetts: The MIT Press, 1992.

CAIAFA, Janice. Trilhos da cidade: viajar no metrô do Rio de Janeiro. Rio de Janeiro: Editora 7Letras, 2013.

CAIAFA, Janice. Aventura das cidades: ensaios e etnografias. Rio de Janeiro: Editora FGV, 2007.

CAIAFA, Janice. Jornadas urbanas: exclusão, trabalho e subjetividade nas viagens de ônibus na cidade do Rio de Janeiro. Rio de Janeiro: Editora FGV, 2002.

CAIAFA, Janice. "C" comme "conducteur": l'automatisation intégrale de la conduite et la reconfiguration des circuits communicationnels dans le métro de Paris. Inédito.

CAIAFA, Janice. Automação e presença humana na Linha 4-Amarela do metrô de São Paulo. Inédito. 
CALLON, Michel. Pour une sociologie des controverses sociologiques. In: AKRICH, Madeleine; CALLON, Michel; LATOUR, Bruno (Orgs.). Sociologie de la traduction: Textes fondateurs. Paris: Presses des Mines, 2006.

COMMUNIQUÉ DE PRESS. STIF, 10 juillet 2013. http://www.amutc.fr /pdf2/MET_STIF_Automatisation_ligne_4.pdf. Acesso em: 16/02/2014.

DAVID, Albert. RATP, la métamorphose: Réalités et théorie du pilotage du changement. Paris: InterEditions, 1995.

DELEUZE, Gilles; GUATTARI, Félix. Mille Plateaux: capitalisme et schizophrénie. Paris: Les Éditions de Minuit, 1980.

HESS, David J. Alternative Pathways in Science and Industry: Activism, Innovation, and the Environment in an Era of Globalization. Cambridge: The MIT Press, 2007.

FELINTO, Erick. Materialidades da comunicação: Por um novo lugar da matéria na Teoria da Comunicação. Revista eletrônica Ciberlegenda, $n^{0}$ 5, 2001. Disponível em: http://www.uff.br/ciberlegenda/ojs/index.php/revista/article/view/308

GUERRAND, Roger-Henri. L'aventure du métropolitain. Paris: La Découverte, 1999.

JOSEPH, Isaac. Météor: Les métamorphoses du métro. Paris: Ed. Economica, 2004.

LA LIGNE 14 FÊTE SES 14 ANS. Disponível em: http://www.ratp.fr/en/ratp/

r_76314/la-ligne-14-fete-ses-14-ans. Acesso em: 16/02/2014.

LATOUR, Bruno. Where Are the Missing Masses? The Sociology of a Few Mundane Artifacts. In: BIJKER, W. E.; LAW, J. (Orgs.), Shaping technology/building society: studies in sociotechnical change. Cambridge: The MIT Press, 1992.

LE NENAON, Kelita; PERREAU, Anne. La modernisation du service public: l'exemple du contrôle des recettes de la RATP, 67 f. Rapport de recherche, Option Gestion Scientifique. École Nationale Supérieure des Mines de Paris, 1992.

LEFEBVRE, Frédéric. L'architecte dans le métro: La gestion de l'esthétique des projets à la RATP. Rapport de recherche, RATP, No 82, 1993.

LEMOS, André. Cultura da Mobilidade. Revista FAMECOS, $\mathrm{n}^{\circ}$ 40, dezembro de 2009 . 
Disponível em: http://revistaseletronicas.pucrs.br/ojs/index.php/ revistafamecos/article/ viewFile/6314/4589

METRO AUTOMATION FACTS, FIGURES AND TRENDS. Union Internationale des Transports Publiques (UITP), s/d. Disponível em: ww.uitp.org. Acesso em: 21/01/2014.

MORLEY, David. Communications and transport: The mobility of information, people and commodities. Media, Culture \& Society, Vol. 33, nº 5, 2011.

PINÇON, Michel; PINÇON-CHARLOT, Monique. Paris Mosaïque: Promenades urbaines. Paris: Calmann-Lévy, 2001.

SÁ, Simone Pereira de. Explorações da noção de materialidade da comunicação. Revista Contracampo, edição especial, $\mathrm{n}^{\mathrm{o}}$ 10/11, 2004. Disponível em: http://www.uff.br /contracampo/index.php/revista/article/view/526/273

TARDE, Gabriel. A opinião e as massas. São Paulo: Martins Fontes, 1992.

THIERY, Olivier. Les modes de certification, de capitalisation et de généralisation des innovations de service: Le cas de la ligne 14. La mise en service du Météor - Ligne 14. Décision de subvention $n^{\circ} 00 \mathrm{MT} 42$, Ministère de l'équipement, des transports et du logement, Juin 2002.

VILLOUTREIX, Frédéric. Modalités d'étude, de conception et d'introduction de systèmes integrés d'automatismes, 339 f. Tese (Doutorado) - École Nationale Supérieure des Mines de Paris, Ingénierie et Gestion, 1990.

Sites

http://www.cartesfrance.fr/carte-france-departement/carte-france-departements.html http://www.ratp.fr

http://www.viaquatro.com.br 